\title{
An evaluation of a multi-component adult weight management on referral intervention in a community setting
}

\author{
Kate Birnie ${ }^{1}$, Lindsey Thomas ${ }^{2,3}$, Clare Fleming ${ }^{3}$, Sarah Phillips ${ }^{2,3}$, Jonathan A. C. Sterne ${ }^{1}$, Jenny L. Donovan ${ }^{1}$ \\ and Julie Craig ${ }^{2,3^{*}}$
}

\begin{abstract}
Background: National Institute for Health and Care Excellence (NICE) guidance on adult weight management recommends interventions are multi-component. We aimed to assess the implementation and health benefits of a primary care referral to an adult multi-component weight management intervention in a community setting. The intervention was offered through Primary care in National Health Service (NHS) South Gloucestershire, UK, from Oct 2008 to Nov 2010, in partnership with statutory, community and commercial providers. The scheme offered 12 weeks' community based concurrent support of dietary (Weight Watchers, WW), physical activity (Exercise on Prescription, EOP) and behavioural change (motivational interviewing) components to obese adults. Funding was available for 600 places.
\end{abstract}

Results: Five hundred and fifty nine participants engaged with the intervention, mean age 48 years, $88 \%$ female. Mean weight loss for all engagers was $3.7 \mathrm{~kg}$ (95\% confidence interval 3.4, 4.1). Participants completing the intervention achieved the largest weight reduction (mean loss $5.9 \mathrm{~kg} ; 5.3,6.6$ ). Achievement of $5 \%$ weight loss was higher in completers $(58 \% ; 50,65)$ compared to non-completers $(19 \% ; 12,26)$ and people who only participated in one commercial component of the intervention (either WW or EOP; $19 \% ; 13,24)$.

Conclusion: A multi-component weight management programme may be beneficial for weight loss, but a randomized controlled trial is needed to establish effectiveness and to evaluate cost.

Keywords: Obesity, Weight management, Diet, Physical activity, Behaviour change, Intervention

\section{Background}

The UK prevalence of adult obesity continues to be a major public health concern, almost a quarter of adults in England are now classified as obese [1] as defined by the World Health Organisation criterion of a body mass index (BMI) of 30 kilograms $(\mathrm{kg}) /$ metre $(\mathrm{m})^{2}$ or above [2]. The impact on the individual can be considerable, as obesity is associated with a number of medical conditions [3], including diabetes [3-5], cardiovascular disease [3,5] and cancer $[3,5,6]$, and obesity is a major economic burden for the population $[7,8]$.

\footnotetext{
*Correspondence: juliesacraig@outlook.com

3 South Gloucestershire Council, Bristol, UK

Full list of author information is available at the end of the article
}

National Health Service (NHS) primary care is an obese patient's first point of access to non-surgical, nonpharmacological weight management treatment. Currently at least 10 million UK adults are eligible for weight management interventions to reduce their risk of morbidity and mortality [1] and thousands of patients are identified daily through NHS initiatives for obesity, cardiovascular management and diabetes prevention. A primary route to weight loss is to achieve a negative energy balance (expending more calories than are consumed). This can be achieved by reducing dietary calorific intake or increasing physical activity or both. Diet and physical activity behaviours are both amenable to change and National Institute for Health and Care Excellence (NICE) guidelines state that multi-component lifestyle 
interventions that include behaviour change strategies to increase people's physical activity levels and reduce dietary energy intake [9] are the treatment of choice.

We aimed to assess the implementation and potential health benefits of a novel multi-component weight management on referral intervention that integrated dietary, physical activity and behavioural change (including motivational interviewing) components in a in a community setting.

\section{Methods}

\section{Study design}

This study was a before and after evaluation of a multicomponent weight management programme ("Weight management on referral"; WMOR) offered through NHS South Gloucestershire, UK, during the period from Oct 2008 to Nov 2010. Usual care prior to WMOR being available was general practitioner (GP) advice only.

\section{Recruitment of participants}

Participants were referred into the scheme from 18 of 22 general practices that adopted the intervention in the South Gloucestershire region of England. Individuals were identified opportunistically by GPs and other health professionals in normal practice and referred to the programme if they met the inclusion criteria.

\section{Inclusion/exclusion criteria}

Individuals were eligible for WMOR if they were: aged 18 years or over, if their BMI was 30 or above, or a BMI $\geq 28$ with co-morbidities, had a 'ready to change' attitude (as assessed by the referring GP) and committed to complete both the physical activity and dietary elements of the intervention, and were comfortable in a group situation. People were excluded if they were currently (or in the last 3 months) on a commercial weight management programme, on anti-obesity drugs, on exercise on prescription, or pregnant.

\section{Sample size}

Funding was available for 600 places.

\section{Intervention}

The WMOR intervention included dietary, physical activity and behavioural change components; aiming to establish behaviour changes by building participants confidence and abilities to carry out exercise and make changes to diet. A commercial partner, Weight Watchers (WW) [10], provided participants with access to local, community-based, group WW meetings. Participants received free vouchers for 12 weekly supervised group sessions. At each meeting group members were weighed, there was a discussion led by the group leader and group members could share information and tips. A partnership with South Gloucestershire Council exercise on prescription team (EOP) [11] provided participants with access to local community-based leisure center gyms for one-to-one physical activity sessions. EOP practitioners are exercise specialists with comprehensive training in physical activity interventions, theory-led behaviour change techniques and dietary training and they delivered the motivational interviewing (MI) aspect of the intervention. MI is a directive focused non-judgemental person-centred counselling style that aims to work with resistance around behaviour change. This support aims to initiate behaviour changes, to strengthen and consolidate participants' commitment and self-confidence to change. Individual goals are agreed and barriers to change, or to engaging with the intervention, are tackled.

The programme started with a $40 \mathrm{~min}$ individual session with baseline assessment, delivered by the EOP practitioner. Participants were helped to identify and set personalised realistic short term (12 week) and longer term goals for their weight and physical activity. The participants then attended 12 weekly sessions of separate dietary and physical activity components. All sessions were accessible via public transport. There was a motivational exit assessment conducted by an EOP practitioner at the end of the programme, where the EOP practitioner focused on helping participants become more selfdirected and to build behaviour change into their daily lives.

\section{Ethics}

This was a service evaluation; therefore ethical approval was not needed. We obtained written consent from patients to allow use, storage and transfer of personal data for NHS South Gloucestershire, Weight Watchers and South Gloucestershire Council.

\section{Measurements}

Participants' weight $(\mathrm{kg})$ and BMI (weight $[\mathrm{kg}] /$ height $[\mathrm{m}]^{2}$ ) were measured objectively at baseline and at the weekly EOP and WW sessions. For this study, information on weight and BMI was used from the EOP sessions if available; otherwise recordings from WW were used. Final weight was the measurement taken at week 12, if available; otherwise the previous available measurement was used. Weight loss was calculated as the baseline weight minus the final weight; percentage weight loss was calculated as weight loss divided by baseline weight. BMI was classified according to the WHO definition of the degree of overweight or obesity in adults: 25-29.9 (overweight), 30-34.9 (obesity class 1), 35-39.9 
(obesity class 2), $\geq 40 \mathrm{~kg} / \mathrm{m}^{2}$ (obesity class 3 ). Physical activity levels were self-reported at baseline and at the weekly EOP sessions. Sedentary levels were considered to be less than 30 min of physical activity with moderate intensity per week and non-sedentary was $\geq 1$ session of being physically active for 30 min per week. Postcodes of participants home addresses were linked to lower super output areas to match to South Gloucestershire deprivation quintiles from the index of multiple deprivation [12], ranging from 1 (least deprived) to 5 (most deprived). The domains used in the Indices of Deprivation 2010 were: income deprivation; employment deprivation; health deprivation and disability; education deprivation; crime deprivation; barriers to housing and services deprivation; and living environment deprivation.

\section{Statistical methods}

All analyses were carried out using Stata version 12 . Chi-square tests and analysis of variance were used to test for differences in baseline characteristics by WMOR completion status. An individual was considered to have completed the intervention if they attended 10 of the 12 sessions, for both EOP and WW. Final weight was compared across completion status subsets controlling for weight at start in linear regression; fully adjusted models controlled for age, sex, baseline activity levels and deprivation quintile. Logistic regression models were used to estimate odds ratios of achieving $5 \%$ weight loss for different WMOR completion status subsets; fully adjusted models controlled for the same characteristics as in the linear regression.

\section{Results}

\section{Participants}

A total of 559 participants engaged with the WMOR intervention by attending the initial motivational assessment (Fig. 1). Of these, 67 participants (12\%) dropped out and did not subsequently engage with any WMOR sessions ('dropouts'). Of the remaining 492 participants, 193 (39 \%) did not follow the intended multi-component intervention and only attended one element (i.e., either WW or EOP, but not both; 'one scheme only attenders'). There were 299 participants who started the intended intervention (i.e., attended both WW and EOP concurrently); of these, 163 (55\%) completed the intervention ('two scheme completers' and 136 (45\%) were noncompleters of both the WW and EOP components ('two scheme non-completers'). Of the non-completers, 118 (87\%) completed one component (either WW or EOP). The mean number of sessions attended across all participants who engaged with the scheme was 7 for both EOP and WW (Table 1).
The mean age of people recruited to the intervention was 48 (standard deviation [SD] 14) years (Table 1). Participants who completed the intervention were on average 53 years, those who dropped out of the intervention were younger, with a mean age of 42 years ( $p$ value for a difference between all subsets $<0.001$ ). Eighty eight percent of participants were female; there was no evidence of a gender difference between the completion subsets $(p=0.7)$. There was an equal distribution of participants from each of the local deprivation quintile areas. Average weight at baseline for all engagers was 102 (SD 19) kg. There was some evidence that baseline weight differed between groups $(\mathrm{p}=0.096)$; the average weight for one scheme only attendees $(105 \mathrm{~kg})$ and dropouts $(106 \mathrm{~kg})$ was slightly higher than two scheme completers $(100 \mathrm{~kg})$ and two scheme non-completers $(102 \mathrm{~kg})$. At baseline, $95 \%$ of participants were sedentary, there was no evidence that baseline physical activity differed between groups $(\mathrm{p}=0.5)$.

\section{Weight loss}

The mean weight loss for all engagers was $3.7 \mathrm{~kg}$ (95\% confidence interval $[\mathrm{CI}] 3.4,4.1$ ) (Table 2). The WMOR completers achieved the largest reduction in weight with a mean loss of $5.9 \mathrm{~kg}$ (95\% CI 5.3, 6.6), which is almost twice the mean weight loss of non-completers (mean loss $3.0 \mathrm{~kg}$; $95 \%$ CI $2.5,3.4$ ), or those that only participated in one element of the intervention (mean loss $2.4 \mathrm{~kg}$; $95 \%$ CI 1.8, 2.9). The average percentage weight loss for all engagers was $3.7 \%$ (95\% CI 3.3, 4.0). Thirty two percent of all participants who engaged with WMOR achieved at least $5 \%$ weight loss and $6 \%$ of engagers achieved $\geq 10 \%$ weight loss. Achievement of $5 \%$ weight loss was higher in those that completed the intervention (58\% participants; $95 \%$ CI 50, 65) compared to the non-completers (19\%, $95 \%$ CI 12, 26) and one scheme only attendees (19\%, 95 \% CI 13, 24).

\section{Comparison of weight loss outcomes by WMOR completion status}

Two scheme non-completers were on average $3.06 \mathrm{~kg}$ (95\% CI 2.18, 3.95; p < 0.001) heavier at their final weight measurement than those who completed the WMOR intervention (Table 3). Two scheme non-completers had $84 \%$ lower odds of achieving $5 \%$ weight loss compared to two scheme completers (OR 0.16; $95 \%$ CI 0.09, 0.28). Participants who only attended one element of the programme (EOP or WW) were on average $3.96 \mathrm{~kg}$ heavier $(95 \%$ CI $3.09,4.83)$ at the end of the programme compared to two scheme completers and had $85 \%$ lower odds of achieving $5 \%$ weight loss (OR 0.15; $95 \%$ CI 0.09, 0.27). Associations were not changed when controlling for age, sex, baseline physical activity and deprivation quintile. 


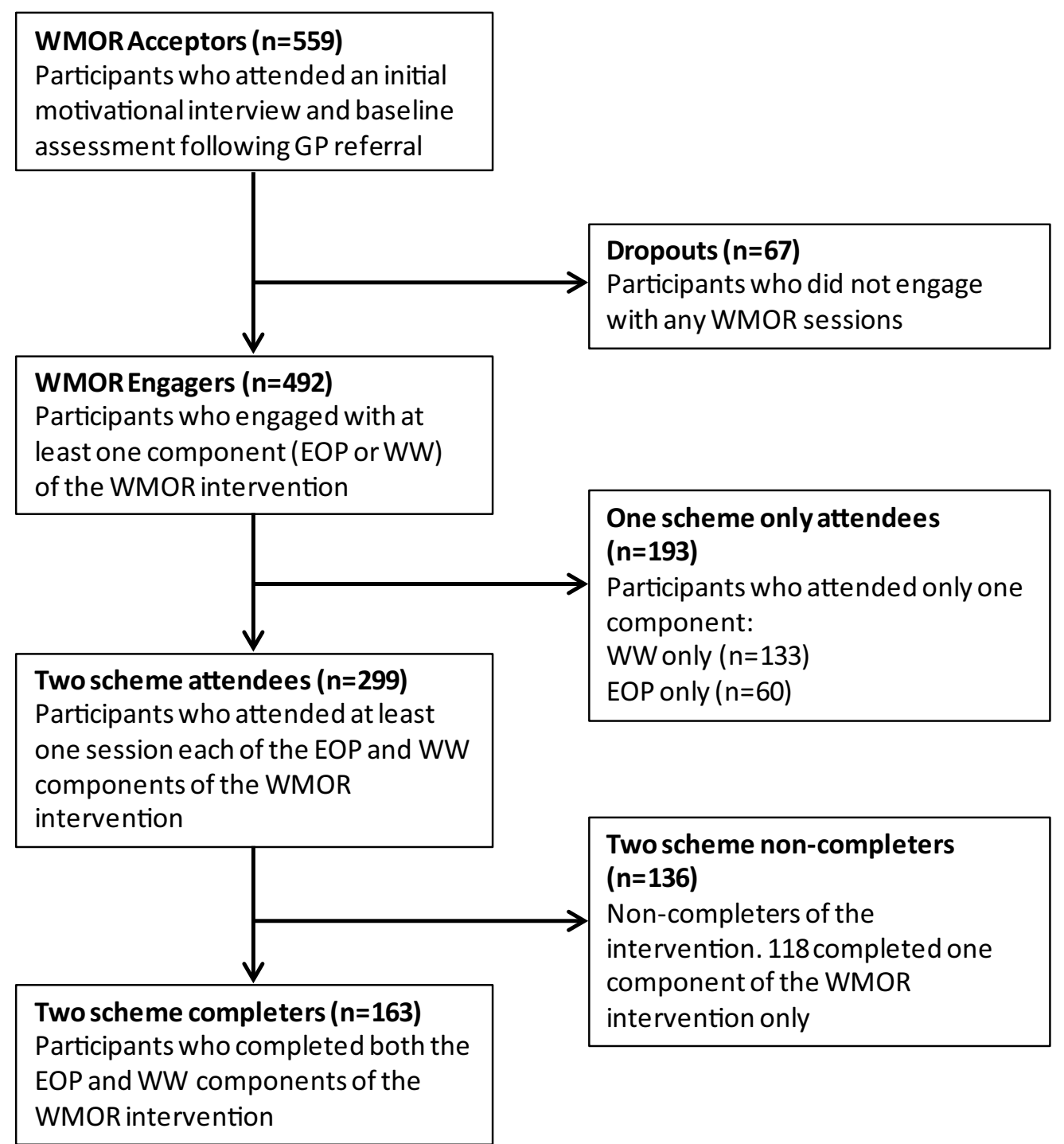

Fig. 1 Flow of patients in the WMOR study

\section{BMI change}

At baseline, $29 \%$ of participants had a BMI in excess of $40 \mathrm{~kg} / \mathrm{m}^{2}$ (obesity class 3 ) (Table 1 ). All groups show a shift of participants from higher to lower obesity classification from the start to the end of the 12 week intervention (Fig. 2). The highest beneficial change of obesity classification is shown by the WMOR two scheme completers, with a shift from 25 to $16 \%$ in obesity class 3 by the end of the intervention, and an increase from 7 to $24 \%$ in the overweight category (BMI 25-29.9, the healthiest obesity classification in the programme).

\section{Discussion}

We performed an assessment of the implementation of a weight management intervention in practice. This aimed to contribute to the final development work before such an intervention could be tested in a randomized controlled trial (RCT). Over the 12 week period, $32 \%$ of participants who engaged with the WMOR intervention and $58 \%$ of those who completed the WMOR programme successfully achieved individual clinically important [13, 14] weight loss of $\geq 5 \%$. Meaningful beneficial shifts were seen in obesity classification for the population group in the programme. At baseline, $95 \%$ participants were 
Table 1 Characteristics of participants

\begin{tabular}{|c|c|c|c|c|c|c|}
\hline & $\begin{array}{l}\text { All WMOR } \\
\text { acceptors }\end{array}$ & $\begin{array}{l}\text { Two scheme } \\
\text { completers }\end{array}$ & $\begin{array}{l}\text { Two scheme } \\
\text { non-completers }\end{array}$ & $\begin{array}{l}\text { One scheme only } \\
\text { attendees }\end{array}$ & Dropouts & $\mathbf{P}$ \\
\hline Participants, N & 559 & 163 & 136 & 193 & 67 & \\
\hline Age, years, mean (SD) & $48(14)$ & $53(15)$ & $49(13)$ & $45(13)$ & $42(12)$ & $<0.001$ \\
\hline Female, N (\%) & $494(88 \%)$ & $144(88 \%)$ & $120(88 \%)$ & $173(90 \%)$ & $57(85 \%)$ & 0.735 \\
\hline \multicolumn{7}{|l|}{ Deprivation quintile ${ }^{a}$} \\
\hline 1 (least deprived) & $96(20 \%)$ & $38(25 \%)$ & $19(15 \%)$ & $31(22 \%)$ & $8(14 \%)$ & \\
\hline 2 & 91 (19\%) & $26(17 \%)$ & $27(22 \%)$ & $23(17 \%)$ & $15(26 \%)$ & \\
\hline 3 & $96(20 \%)$ & 34 (23 \%) & $21(17 \%)$ & $32(23 \%)$ & $9(16 \%)$ & \\
\hline 4 & $92(20 \%)$ & $26(17 \%)$ & $28(23 \%)$ & 24 (17\%) & $14(24 \%)$ & \\
\hline 5 (most deprived) & $96(20 \%)$ & 27 (18\%) & $29(23 \%)$ & $28(20 \%)$ & $12(21 \%)$ & 0.403 \\
\hline Missing data & 88 & 12 & 12 & 55 & 9 & \\
\hline \multicolumn{7}{|l|}{ Baseline characteristics } \\
\hline Weight, kg, mean (SD) & $102(19)$ & $100(18)$ & $102(21)$ & 105 (19) & $106(20)$ & 0.096 \\
\hline \multicolumn{7}{|l|}{ BMI, N (\%) } \\
\hline $25-29.9$ & $30(5 \%)$ & $11(7 \%)$ & $7(5 \%)$ & $9(5 \%)$ & $3(5 \%)$ & \\
\hline $30-34.9$ & $181(32 \%)$ & 60 (37\%) & $48(35 \%)$ & $55(29 \%)$ & $18(27 \%)$ & \\
\hline $35-39.9$ & $183(33 \%)$ & $51(31 \%)$ & $41(30 \%)$ & $69(36 \%)$ & $22(33 \%)$ & \\
\hline $40+$ & $164(29 \%)$ & $41(25 \%)$ & 40 (29\%) & 60 (31\%) & $23(35 \%)$ & 0.699 \\
\hline \multicolumn{7}{|l|}{ Sedentary physical } \\
\hline Activity levels, N (\%) & $486(95 \%)$ & 157 (97 \%) & $127(95 \%)$ & 139 (93 \%) & $63(95 \%)$ & 0.513 \\
\hline \multicolumn{7}{|l|}{ Mean sessions attended } \\
\hline EOP, mean (range) & $7(0-12)$ & $12(11-12)$ & $10(1-12)$ & $10(2-12)^{b}$ & $0(0-0)$ & $<0.001$ \\
\hline WW, mean (range) & $7(0-12)$ & $12(10-12)$ & $7(1-12)$ & $6(1-12)^{b}$ & $0(0-0)$ & $<0.001$ \\
\hline
\end{tabular}

a South Gloucestershire deprivation quintile

b For one-scheme only, calculated for those that attended each single scheme separately

Table 2 Weight loss achieved at 12 weeks

\begin{tabular}{|c|c|c|c|c|c|}
\hline & $\mathbf{N}$ & $\begin{array}{l}\text { Weight loss kg, } \\
\text { Mean }(95 \% \mathrm{Cl})\end{array}$ & $\begin{array}{l}\text { Mean percentage } \\
\text { weight loss }(95 \% \mathrm{Cl})\end{array}$ & $\begin{array}{l}\text { Percent achieving } 5 \% \\
\text { weight loss }(95 \% \mathrm{Cl})\end{array}$ & $\begin{array}{l}\text { Percent achieving } 10 \% \\
\text { weight loss }(95 \% \mathrm{Cl})\end{array}$ \\
\hline WMOR engagers & 492 & $3.7(3.4,4.1)$ & $3.7 \%(3.3,4.0)$ & $32 \%(28,36)$ & $6 \%(4,8)$ \\
\hline Two scheme completers & 163 & $5.9(5.3,6.6)$ & $6.0 \%(5.4,6.6)$ & $58 \%(50,65)$ & $12 \%(4,17)$ \\
\hline $\begin{array}{l}\text { Two scheme non-com- } \\
\text { pleters }\end{array}$ & 136 & $3.0(2.5,3.4)$ & $2.9 \%(2.4,3.3)$ & $19 \%(12,26)$ & $0 \%$ \\
\hline $\begin{array}{l}\text { One scheme only } \\
\text { attendees }\end{array}$ & 193 & $2.4(1.8,2.9)$ & $2.3 \%(1.8,2.8)$ & $19 \%(13,24)$ & $4 \%(1,7)$ \\
\hline
\end{tabular}

sedentary; participants who carried out the EOP element of the intervention will have increased their physical activity levels during the study period. If sustained, these increases may deliver further improvements in health, independent of effects of weight loss and support maintenance of the weight loss achieved for a longer time period [15]. Participants who completed the WMOR programme achieved better outcomes (greater weight loss and achievement of $5 \%$ weight loss) compared to noncompleters and one scheme only attendees (i.e., WW or EOP but not both).
The Lighten Up RCT reported the effectiveness for weight loss of a range of 12 week commercial or primary care led weight loss programmes compared with a minimal control of free activity vouchers [16]. Patients on commercial programmes were more successful in losing weight than those in NHS primary care and pharmacy programmes, at 12 weeks [mean difference 2.3 (1.3-3.4) $\mathrm{kg}$ ] and the commercial provider used in our study, Weight Watchers, was the most successful of the providers examined. A service evaluation of three commercial providers of NHS primary care slimming on referral 
Table 3 Final mean weight difference from linear regression and odds ratios for $5 \%$ weight loss from logistic regression by WMOR completion subsets

\begin{tabular}{|c|c|c|c|}
\hline & $\mathrm{N}$ & $\begin{array}{l}\text { Mean weight difference } \\
\text { in } \mathrm{kg}(95 \% \mathrm{Cl})\end{array}$ & $\begin{array}{l}\text { Odds ratio for } 5 \% \text { weight } \\
\text { loss }^{\text {b }}(95 \% \mathrm{Cl})\end{array}$ \\
\hline \multicolumn{4}{|l|}{ Unadjusted models } \\
\hline Two scheme completers & 150 & $\operatorname{Ref}(0)$ & $\operatorname{Ref}(1)$ \\
\hline Two scheme non-completers & 121 & $3.06(2.18,3.95)$ & $0.16(0.09,0.28)$ \\
\hline One scheme only attendees & 129 & $3.96(3.09,4.83)$ & $0.15(0.09,0.27)$ \\
\hline$P$ & & $<0.001$ & $<0.001$ \\
\hline \multicolumn{4}{|l|}{ Adjusted models ${ }^{c}$} \\
\hline Two scheme completers & 150 & $\operatorname{Ref}(0)$ & $\operatorname{Ref}(1)$ \\
\hline Two scheme non-completers & 121 & $3.10(2.20,4.00)$ & $0.15(0.09,0.27)$ \\
\hline One scheme only attendees & 129 & $4.05(3.15,4.94)$ & $0.16(0.09,0.28)$ \\
\hline$P$ & & $<0.001$ & $<0.001$ \\
\hline
\end{tabular}

${ }^{a}$ Linear regression model for weight at end, controlling for weight at start

b Logistic regression model for whether $5 \%$ weight loss was achieved

c Models control for age, sex, baseline physical activity levels and deprivation quintile. Analyses were carried out on participants with complete data across these variables

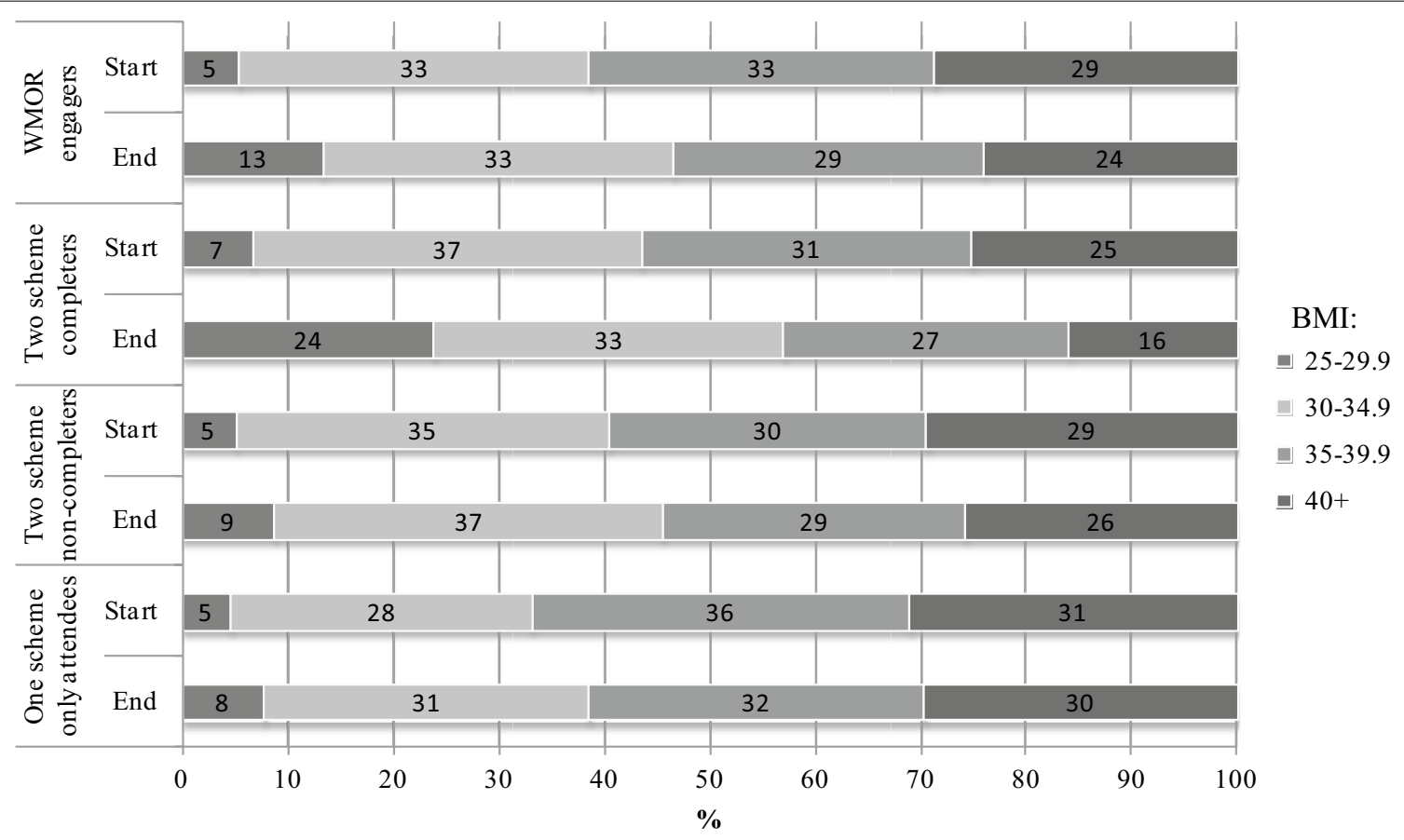

Fig. 2 BMI classifications of WMOR participants at the start and end of the 12 week intervention

in North Somerset found that found WW provided a greater value for money than other providers with lower costs per kg lost, per percentage bodyweight lost and per BMI point change [17].

Outcomes in our study were similar to an audit of patients referred by the NHS to WW [18]; the average percentage weight loss for engagers in our study was $3.7 \%$ compared to $3.1 \%$. Our study showed that clinically useful weight loss of $5 \%$ was achieved by $32 \%$ of engagers and the WW audit showed $33 \%$ of all commenced referrals achieved a $5 \%$ weight loss. The results for engagers from this study were slightly lower than two other non-randomized service evaluations comparing referral to commercial providers at 12 weeks $[17,19]$. Our multi-component intervention was more intensive which may have led to the lower percentage of 
completers in the study, $33 \%$ compared to $64 \%$ [19] and $54 \%$ [17]. As in our study, others have found that participants who completed the intervention achieved more weight loss than non-completers $[17,18]$. When comparing outcomes for completers our results are comparable: NHS South Gloucestershire patients achieved a mean weight loss of $5.9 \mathrm{~kg}$ compared to $6.1 \mathrm{~kg}$ [19] and $6.4 \mathrm{~kg}$ [17]; and $58 \%$ of completers achieved a $5 \%$ weight loss compared to $61 \%$ [17]. A key aspect to achieving health gains associated with dietary weight loss interventions is to sustain the weight lost and behaviour change achieved beyond 12 weeks. The Lighten Up RCT showed that a 12 week group based programme of weight management can also result in clinically beneficial amounts of weight loss that are sustained at one year [16]. However, obesity is a chronic, relapsing condition and the sustainability of weight loss achieved in short term interventions cannot be assumed. Around a third of participants who achieved a $\geq 5 \%$ weight loss at the end of a 12 week commercial weight management programme regained weight within a year [16]. Hence, there is scope for improving outcomes from referral to primarily dietary focused lifestyle weight management interventions. Systematic reviews of RCTs have demonstrated that calorie restricted diets alone are more effective for weight loss than physical activity alone [20-22]. It has also been shown that dietary interventions can be enhanced: adding physical activity, particularly supervised physical activity, to dietary interventions increases weight loss by $2-3 \mathrm{~kg}[20,23]$ at 1 year of follow up; adding established behaviour change techniques including motivational interviewing to weight loss interventions also increases their effectiveness [24, 25].

This study illustrates the potential benefits of implementing an adult multi-component weight management on referral intervention that includes dietary, physical activity and behavioural change elements, in a community setting. The programme targeted the initiation and establishment of behaviour change for participants. Limited primary care capacity and funding to treat obesity were the drivers for the study to use existing infrastructure based in the community to deliver the intervention components. We achieved a low cost, large capacity accessible intervention. Strengths of the intervention are that it was multi-component, as NICE guidelines recommend [9]. We are not aware of any other studies that have evaluated an intervention with these multiple components in a UK primary care population. The partnership working between PCT, GPs, local authority and Weight Watchers ensured the delivery approach of this integrated multi component service was truly patient centred.

Participants who completed all elements of the intervention achieved the most weight loss, but a major limitation is that the study was observational. It is plausible that completers were more motivated than non-completers, and weight loss differences between groups was due to baseline confounding rather than the effect of the intervention. Individuals were required to have a 'ready to change' attitude to be eligible for the intervention, therefore they may have achieved the observed weight loss over the study period without the intervention. The logical next step would be to carry out an RCT of the multi-component intervention. We do not have data on longer term outcomes of study participants, which would be useful to show whether weight loss is maintained, and further research is needed to assess the long-term clinical outcomes and the cost-effectiveness of referral to a multi-component intervention. An additional limitation was that when participants did not attend the exercise element of the intervention, we could not obtain weight measurements from the EOP sessions. In this case, we used measurements from WW sessions, these were made and recorded by WW group leaders and were not collected for the purpose of research. The intervention was only carried out in one region, South Gloucestershire, and may not be nationally representative. The participants had to have a 'ready to change' attitude, willing to complete both components and be comfortable in a group situation when they joined the programme, and so if this intervention were rolled out more broadly, response rates might be lower than seen here.

\section{Conclusions}

We have demonstrated that it is possible to implement a multi-component adult weight management intervention in a community setting. The results from this study suggest the multi-component weight management programme may be beneficial for weight loss for obese individuals, but an RCT is needed to establish effectiveness and to evaluate cost.

\section{Abbreviations}

BMI: body mass index; Cl: confidence interval; EOP: exercise on prescription; GP: general practitioner; kg: kilogram; m: metre; Ml: motivational interviewing; NHS: National Health Service; NICE: National Institute for Health and Care Excellence; RCT: randomized controlled trial; SD: standard deviation; WMOR: weight management on referral; WW: Weight Watchers.

\section{Authors' contributions}

LT and JC contributed to the study design. CF and JC coordinated the data collection. KB and SP performed the statistical analysis. JS supervised the statistical analysis. JD, JS, JC, KB and SP interpreted the data. KB and JC wrote the first draft of the paper. All authors read and approved the final manuscript.

\section{Author details}

${ }^{1}$ School of Social and Community Medicine, University of Bristol, Bristol, UK. ${ }^{2}$ NHS South Gloucestershire, Bristol, UK. ${ }^{3}$ South Gloucestershire Council, Bristol, UK. 


\section{Acknowledgements}

We thank Nicola Ellis for her contribution to the study design. The Weight management on referral scheme was funded by South Gloucestershire Council and NHS South Gloucestershire Primary Care Trust. The work for this manuscript was supported by North Bristol NHS Trust. JS and JD were supported by National Institute for Health Research (NIHR) Senior Investigator Awards (NF-SI0611-10168 and NF-SI-0512-10119). KB is supported by a Medical Research Council UK fellowship (RD1826). None of the funding bodies influenced the data collection, analysis or its interpretation for this paper. The views expressed are those of the authors and not necessarily any funding body.

\section{Competing interests}

The authors declare that they have no competing interests.

Received: 13 October 2015 Accepted: 2 February 2016 Published online: 17 February 2016

\section{References}

1. Tabassum F. Adult anthropometric measures, overweight and obesity. In: Craig R, Hirani V, editors. Health Survey for England 2009. Health and lifestyles, vol. 1. London: The Health and Social Care Information Centre; 2010

2. World Health Organisation. Global database on body mass index. Geneva: World Health Organisation, 2012.

3. Guh DP, Zhang W, Bansback N, Amarsi Z, Birmingham CL, Anis AH. The incidence of co-morbidities related to obesity and overweight: a systematic review and meta-analysis. BMC Public Health. 2009;9:88.

4. Weinstein AR, Sesso HD, Lee IM, Cook NR, Manson JE, Buring JE, Gaziano JM. Relationship of physical activity vs body mass index with type 2 diabetes in women. JAMA. 2004;292(10):1188-94.

5. Folsom AR, Kushi LH, Anderson KE, Mink PJ, Olson JE, Hong CP, Sellers TA, Lazovich D, Prineas RJ. Associations of general and abdominal obesity with multiple health outcomes in older women: the lowa Women's Health Study. Arch Intern Med. 2000;160(14):2117-28.

6. Lukanova A, Bjor O, Kaaks R, Lenner P, Lindahl B, Hallmans G, Stattin P. Body mass index and cancer: results from the Northern Sweden Health and Disease Cohort. Int J Cancer. 2006;118(2):458-66.

7. Wang YC, McPherson K, Marsh T, Gortmaker SL, Brown M. Health and economic burden of the projected obesity trends in the USA and the UK. Lancet. 2011;378(9793):815-25.

8. Scarborough P, Bhatnagar P, Wickramasinghe KK, Allender S, Foster C, Rayner M. The economic burden of ill health due to diet, physical inactivity, smoking, alcohol and obesity in the UK: an update to 2006-07 NHS costs. J Public Health (Oxf). 2011;33(4):527-35.

9. National Institute for Health and Clinical Excellence. Managing overweight and obesity in adults - lifestyle weight management services. In: NICE public health guidanc. 53 ed; 2014. https://www.nice.org.uk/ guidance/ph53

10. http://www.weightwatchers.co.uk/

11. Exercise on Prescription. In: South Gloucestershire Council. 2012.

12. http://data.gov.uk/dataset/index-of-multiple-deprivation
13. Tuomilehto J, Lindstrom J, Eriksson JG, Valle TT, Hamalainen H, IlanneParikka P, Keinanen-Kiukaanniemi S, Laakso M, Louheranta A, Rastas $M$, et al. Prevention of type 2 diabetes mellitus by changes in lifestyle among subjects with impaired glucose tolerance. N Engl J Med. 2001;344(18):1343-50.

14. Imayama I, Ulrich CM, Alfano CM, Wang C, Xiao L, Wener MH, Campbell $\mathrm{KL}$, Duggan C, Foster-Schubert KE, Kong A, et al. Effects of a caloric restriction weight loss diet and exercise on inflammatory biomarkers in overweight/obese postmenopausal women: a randomized controlled trial. Cancer Res. 2012;72(9):2314-26

15. Shaw KA, Gennat HC, O'Rourke P, DelMar C. Exercise for overweight or obesity. Cochrane Database Syst Rev. 2006;(4):CD003817. doi:10.1002/14651858.CD003817.pub3.

16. Jolly K, Lewis A, Beach J, Denley J, Adab P, Deeks JJ, Daley A, Aveyard P. Comparison of range of commercial or primary care led weight reduction programmes with minimal intervention control for weight loss in obesity: lighten up randomised controlled trial. BMJ. 2011;343:d6500.

17. Dixon KJ, Shcherba S, Kipping RR. Weight loss from three commercial providers of NHS primary care slimming on referral in North Somerset: service evaluation. J Public Health (Oxf). 2012;34:555.

18. Ahern AL, Olson AD, Aston LM, Jebb SA. Weight watchers on prescription: an observational study of weight change among adults referred to weight watchers by the NHS. BMC Public Health. 2011;11:434.

19. Lloyd A, Khan R. Evaluation of healthy Choices: a commercial weight loss programme commissioned by the NHS. Perspect Public Health. 2011;131(4):177-83.

20. Wu T, Gao X, Chen M, van Dam RM. Long-term effectiveness of dietplus-exercise interventions vs. diet-only interventions for weight loss: a meta-analysis. Obes Rev. 2009;10(3):313-23.

21. Avenell A, Broom J, Brown TJ, Poobalan A, Aucott L, Stearns SC, Smith WC, Jung RT, Campbell MK, Grant AM. Systematic review of the long-term effects and economic consequences of treatments for obesity and implications for health improvement. Health Technol Asses. 2004;8(21):1-182.

22. Drombrowsji SU, Avenell A, Sniehotta FF. Behavioural interventions for obese adults with additional risk factors for morbidity: systematic review of effects on behaviour, weight and disease risk factors. Obes Facts. 2010;3(6):377-96.

23. Greaves CJ, Sheppard KE, Abraham C, Hardeman W, Roden M, Evans PH, Schwarz P. Systematic review of reviews of intervention components associated with increased effectiveness in dietary and physical activity interventions. BMC Public Health. 2011;11:119.

24. Shaw KA, O'Rourke P, Del Mar C, Kenardy J. Psychological interventions for overweight or obesity. Cochrane Database Syst Rev. 2005;(2):CD003818. doi:10.1002/14651858.CD003818.pub2.

25. Armstrong MJ, Mottershead TA, Ronksley PE, Sigal RJ, Campbell TS, Hemmelgarn BR. Motivational interviewing to improve weight loss in overweight and/or obese patients: a systematic review and meta-analysis of randomized controlled trials. Obes Rev. 2011;12(9):709-23.

\section{Submit your next manuscript to BioMed Central and we will help you at every step:}

- We accept pre-submission inquiries

- Our selector tool helps you to find the most relevant journal

- We provide round the clock customer support

- Convenient online submission

- Thorough peer review

- Inclusion in PubMed and all major indexing services

- Maximum visibility for your research

Submit your manuscript at www.biomedcentral.com/submit

C Biomed Central 